\title{
Novel deletion and 2397 G>T mutations of the EXT1 gene identified in two Chinese pedigrees with hereditary multiple exostoses using exon sequencing
}

\author{
Yang Shen ${ }^{1 \#}$, Lei Zhang ${ }^{2 \#}$, Bosong Chen ${ }^{1}$, Liangchao Dong ${ }^{1}$, Yicheng Wang ${ }^{1}$, Sun Wang ${ }^{1}$ \\ ${ }^{1}$ Department of Orthopedics, Shanghai Children's Hospital, Shanghai Jiao Tong University, Shanghai, China; ${ }^{2}$ The First Maternity and Infant \\ Hospital Affiliated to Tongji University, Shanghai, China \\ Contributions: (I) Conception and design: Y Shen; (II) Administrative support: Y Shen; (III) Provision of study materials or patients: L Zhang; (IV) \\ Collection and assembly of data: L Zhang; (V) Data analysis and interpretation: B Chen; (VI) Manuscript writing: All authors; (VII) Final approval of \\ manuscript: All authors. \\ \#These authors contributed equally to this work. \\ Correspondence to: Sun Wang. Department of Orthopedics, Shanghai Children's Hospital, Shanghai Jiao Tong University, Shanghai 200062, China. \\ Email: oge8198@dingtalk.com.
}

\begin{abstract}
Background: Hereditary multiple exostoses (HME), a rare genetic pediatric disorder, has a peculiar pathogenic mechanism. The results of previous studies have shown that HME is associated with mutations of the EXT1 and EXT2 genes at a molecular genetics level. In our study, two families who received therapy in the Department of Orthopedics of Shanghai Children's Hospital between June, 2017 and November, 2018 were recruited, and a mutational analysis of the EXT1 genes was conducted to further elucidating the relationship between HME and EXT1.

Methods: Venous blood samples were collected from individuals with HME and their families. Exon sequencing and RT-PCR were performed to comprehensively analyze 11 exons of the EXT1 gene.

Results: The deletion of exon 7 and the 2397 G>T mutation in exon 7 caused deletion mutation and nonsense mutation only in the HME patients. The mutations in exon 7 were tested and verified by Sanger sequencing. RT-PCR showed that the mRNA expression of EXT1 was significantly decreased in the mutation samples compared with the normal samples, which exerted a great influence on the function of EXT1.

Conclusions: This study identified new mutation sites for the pathogenesis of HME and further clarified the relationship between HME and EXT1.
\end{abstract}

Keywords: Hereditary multiple exostoses (HME); EXT1 gene; deletion mutation; exon sequencing

Submitted May 15, 2020. Accepted for publication Aug 21, 2020.

doi: $10.21037 / \mathrm{tp}-20-191$

View this article at: http://dx.doi.org/10.21037/tp-20-191

\section{Introduction}

Hereditary multiple exostoses (HME), an autosomal dominant genetic disease, is characterized by chondrogenic osteogenesis and multiple osteochondroma. In Western countries, HME has a prevalence of 1/50,000 (1,2). HME clinically manifests as cartilage-capped bony protrusions from the long metaphyseal end perpendicular to the long bone. Bone warts can occur in any bone, but long bones are especially susceptible and the distal end of the femur and the upper end of the tibia are sites with a high probability of occurrence. Other clinical manifestations include chronic pain syndromes, limb dysfunction, skeletal developmental deformity, short stature, scoliosis, and neurovascular alteration. Although HME is a benign disease, $1-2 \%$ of patients progress to chondrosarcoma, a malignant tumor (3). Currently, the drug treatment for multiple osteochondroma is 
still in the laboratory research phase. Some researchers screen small molecules that function in a similar manner within chondrocyte cultures, as well as, in reducing the development and frequency of osteochondromas within various mouse models of HME. The current treatment method of HME is still based on surgery. Surgery is the recommended treatment for removing tumors and improving limb function and the appearance of deformities, as well as for suspected cases of malignant transformation. Simple tumor resection is mainly suitable for large tumors and tumors that compress the surrounding muscle and nerves $(4,5)$. However, the best surgical timing and method for patients with different disease stages and needs have proved controversial. Previous studies have discussed several theories on the pathogenesis of HME such as abnormal embryo growth and development, dislocation and displacement of growth plate and the metaphyseal periosteum is not fully developed. However, its exact pathogenic mechanism is still unclear. The mechanism of HME is an extremely complicated process. Because of its genetic heterogeneity, HME and mutations of EXT (exotosin) are interrelated in molecular genetics research. Most of the pathogenic genes found in studies to date have been concentrated in the EXT1 (exotosin-1, MIM \# 608117) gene and the EXT2 (exotosin-2, MIM \# 608210) gene (6). In previous studies, frameshift, nonsense, or splicing mutations have been the most common types of EXT mutations found, and large fragment mutations have rarely emerged (7). Mutations in the EXT1 or EXT2 gene lead to partial loss of the function of its encoded protein, which lead to cartilage internalization, bone development disorders and osteochondroma formation which can be through signal transduction systems such as Ihh, FGF, and BMP.

The EXT1 gene located on chromosome 8q23-q24 and the EXT2 gene located on chromosome 11p11-p12 contain 11 and 16 exons, respectively. Linkage analysis identified the EXT3 gene on chromosome 19p (8). However, the EXT3 gene has not yet been cloned and related research is limited. EXT1 and EXT2 mutations were found in 70-94\% of patients with human HME and can exist in one or both genes. EXT1 and EXT2 genes are highly homologous (9). Their coding products localized in the Golgi apparatus are widely present in all somatic cells as type II transmembrane glycoproteins $(10,11)$. The two form a heterologous oligomeric complex, heparan sulfate polymerase, which has a high level of glycosyltransferase activity. Heparan sulfate polymerase, a heparan sulfate synthetase, catalyzes the alternate attachment of glucuronic acid and $\mathrm{N}$-acetyl glucosamine to extend the peptide chain, forming heparan sulfate. The heparan sulfate then covalently bonds to the core protein to form heparan sulfate proteoglycan (HSPG). Proteoglycans exist on the surface of chondrocyte membranes and extracellular matrix involved in signal transduction, cell proliferation, and differentiation $(12,13)$. The germline EXT mutation can influence the production of proteoglycans and the proliferation and differentiation of chondrocytes, which further reduces HS production at perichondrial sites, thus facilitating the formation of osteochondroma. In our previous research, we found three updated mutations of EXT1 (p.Thr332Ser, p.Arg405Lys, and p.Trp412Arg) which are important to the prevention and diagnosis of HME. Despite the recent significant advances, the study of the pathogenic mechanism of HME is still underway, and methods for treatment have yet to be developed. HME still plagues the quality of life of most patients. Given the relationship between the EXT gene and HME, novel insights into the specific role of EXT1 in HME are still greatly needed. The present study focuses on the novel mutations of EXT1 that has a close contact with the occurrence of HME. The quality of life and health complications for participants in our study are exactly coincided with HME, which may own great research value. The research with latest technology aims to determine related mutations that have not been identified before. We present the following article in accordance with the MDAR reporting checklist (available at http://dx.doi.org/10.21037/ tp-20-191).

\section{Methods}

\section{Pedigree survey and sample collection}

Two families were recruited from the Department of Orthopedics of Shanghai Children's Hospital between June, 2017 and November, 2018. Venous blood samples were collected from the study participants. Genomic DNA was extracted from peripheral blood according to the standard procedures for exome sequencing. All procedures performed in this study involving human participants were in accordance with the Declaration of Helsinki (as revised in 2013). The study was approved by Ethics Committee of the Department of Orthopedics of Shanghai Children's Hospital (NO.: 2017023) and informed consent was taken from all the patients. 
Table 1 The polymerase chain reaction primers used for the EXT1 gene and the anticipated length

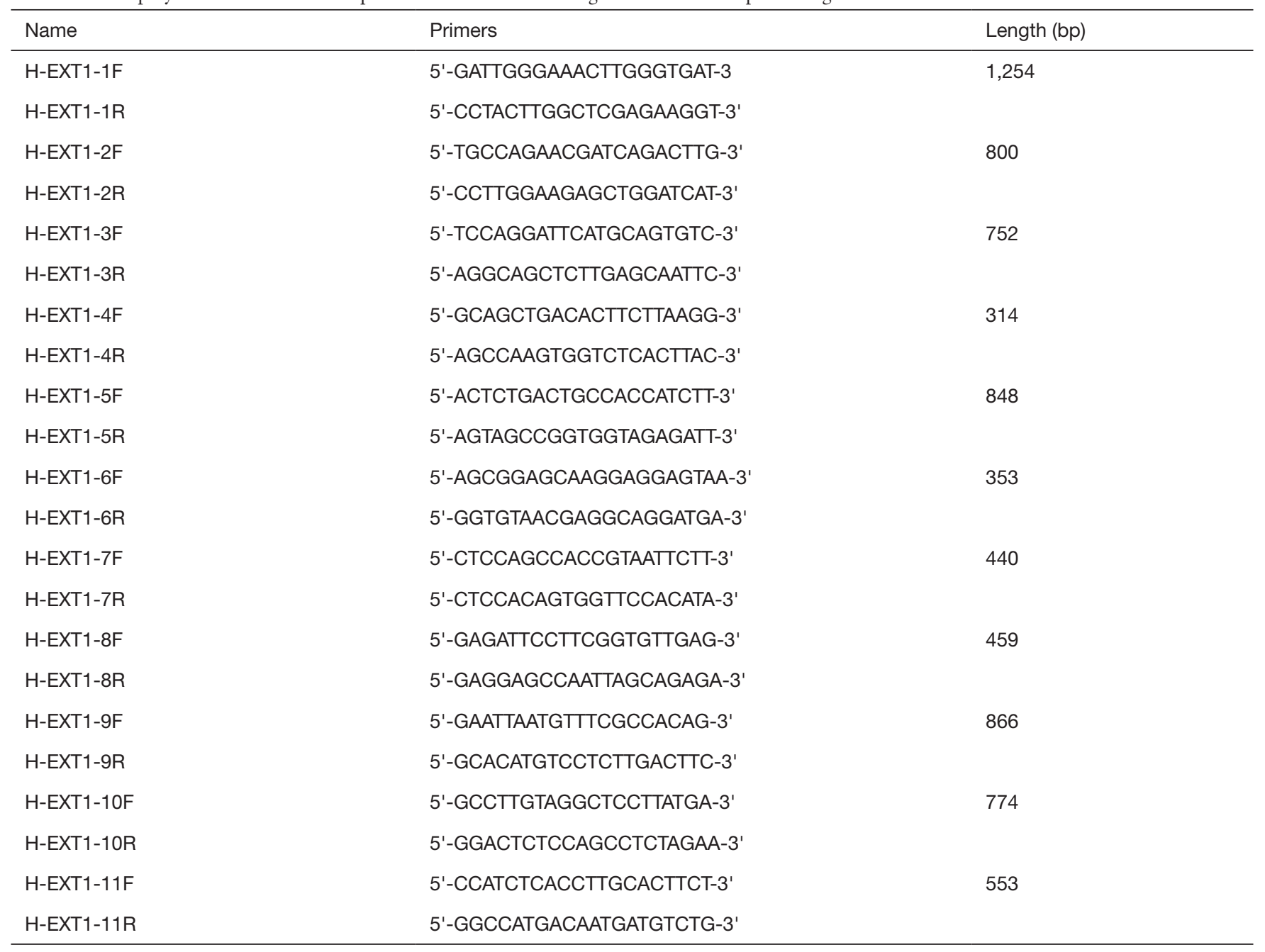

\section{Extraction of DNA and RNA}

Venous blood samples were collected in EDTAanticoagulant vacuum blood collection tubes from 11 pedigrees and stored in $-20^{\circ} \mathrm{C}$ for the research. Total DNA and RNA were extracted from the blood according to the manufacturer's instructions. The concentration and purity of the DNA and RNA were detected by measuring the absorbance at 260 and at $280 \mathrm{~nm}$ with the DU800 UV spectrophotometer (Beckman, USA).

\section{Sequencing of the EXT1 gene and design of primers}

The DNA and mRNA sequences of the EXT1 gene (GenBank NG_007455; NM_000127) to verify the exon regions were obtained from the NCBI website (www.ncbi. nlm.nih.gov/). According to the coding region of the EXT gene, the exon and intron junction regions, primers were designed using software, including 11 pairs of EXT1 gene polymerase chain reaction (PCR) primers and 5 pairs of cross-intron primers to cover the 11 coding regions of the EXT1 gene and their flanking sequences. The proportion of GC was $50-55 \%$ in these primers and the annealing temperature was $57^{\circ} \mathrm{C}$. The primers were synthesized by Shanghai Jierui Biotech Biotech Co., Ltd. (Tables 1,2). PCR for the EXT1 gene was performed with the DNA templates of the family members using a kit with GC Buffer (Takara, Japan). The PCR protocol was consistent with our previous method. The mixture used for PCR $(25 \mu \mathrm{L})$ 
Table 2 The cross-intron primers used for the EXT1 gene and the anticipated length

\begin{tabular}{|c|c|c|}
\hline Name & Primers & Length (bp) \\
\hline EXT1CDNA1884C & 5'-CTTCAGAGAATGGCAACTCC-3' & \\
\hline EXT1CDNA1865 & 5'-GGAGTTGCCATTCTCTGAAG-3' & 587 \\
\hline EXT1CDNA2452C & 5'-GCGTCTGTGATGATGTTGTC-3' & \\
\hline EXT1CDNA2765C & 5'-CACAGCAGACACCAGGAAGT-3' & \\
\hline EXT1CDNA2508 & 5'-TTCACAGTGTGGCAGAGCTT-3' & 680 \\
\hline EXT1CDNA3188C & 5'-CAGGAGCCAGGAGTTGAGTT-3' & \\
\hline EXT1CDNA2379 & 5'-GTCGTCGTCATTGAAGGAGA-3' & 112 \\
\hline
\end{tabular}

included $3 \mu \mathrm{L}$ of template, $1 \mu \mathrm{L}$ of each primer, $2 \mu \mathrm{L}$ of $2.5 \mathrm{mM}$ dNTP, $0.2 \mu \mathrm{L}$ of EX TaqE, $12.5 \mu \mathrm{L}$ of $2 \times \mathrm{GC}$ buffer and $5.3 \mu \mathrm{L}$ of $\mathrm{ddH}_{2} \mathrm{O}$. All PCR programs conditions can be listed as follows: pre-denaturation at $95{ }^{\circ} \mathrm{C}$ for $5 \mathrm{~min}$, a total of 32 cycles of denaturation at $95{ }^{\circ} \mathrm{C}$ for $45 \mathrm{~s}$, annealing at $57{ }^{\circ} \mathrm{C}$ for $45 \mathrm{~s}$ and extension at $72{ }^{\circ} \mathrm{C}$ for $45 \mathrm{~s}$, and a final extension at $72^{\circ} \mathrm{C}$ for $10 \mathrm{~min}$. The PCR products were stored at $4{ }^{\circ} \mathrm{C}$. When the concentration and purity of the PCR products were up to standard, they were subjected to sequencing by the Shanghai Majorbio Company. The purified PCR products sequenced with BigDye 3.1 (Applied Biosystems, life technologies) in the following PCR programme: denaturation $4 \mathrm{~min}$ at $94{ }^{\circ} \mathrm{C}, 25$ cycles of $30 \mathrm{sec}$ at $94{ }^{\circ} \mathrm{C}, 20 \mathrm{sec}$ at $50^{\circ} \mathrm{C}$ and $3 \mathrm{~min}$ at $60^{\circ} \mathrm{C}$. The sequences were analyzed with an ABI PRISM 3730 DNA Analyzer (Applied Biosystems, Thermo Fisher Scientific, Inc.). All the mutations detected in the period was confirmed by digestion of each PCR product with the corresponding enzyme and experienced strict quality control. The possible pathogenic mutations screened from the sequencing were manually re-analyzed and would be proved to be novel variants.

\section{Detection of DNA and RNA amplification primers}

The results of PCR amplification of all exons of the EXT1 gene after agarose gel electrophoresis and imaging are shown in Figure 1. All of the specific primer amplification bands were clear. The length of the amplified fragment was about 100-1,200 bp, which is in line with the target PCR amplification, and the PCR product could be sequenced.

\section{$R T-q P C R$}

Total RNA was extracted from the venous blood samples using the methods previously described. cDNA was generated with a reverse transcription kit (Promega, Madison, Wisconsin, USA). Quantitative PCR reagents were applied to detect the mRNA level of EXT1. Real-time PCR was performed according to manufacturer's protocol.

\section{Statistical analysis}

All data were expressed as the mean \pm SEM. Comparisons between two groups were made using Student's $t$-test. A P value of $<0.05$ was considered to be statistically significant. Statistical analyses were performed with GraphPad Prism 6.0 (Graph Pad Prism Software) and IBM SPSS Statistics version 14.0 for Windows (IBM Corp, New York, USA).

\section{Results}

\section{Clinical manifestation}

The baseline characteristics of the two families are presented in Figure 2. All of the participants underwent a general examination and were classified according to the clinical criteria of HME. The results showed that the males were more likely to suffer from HME than the females and present with more severe symptoms. The tumors were 

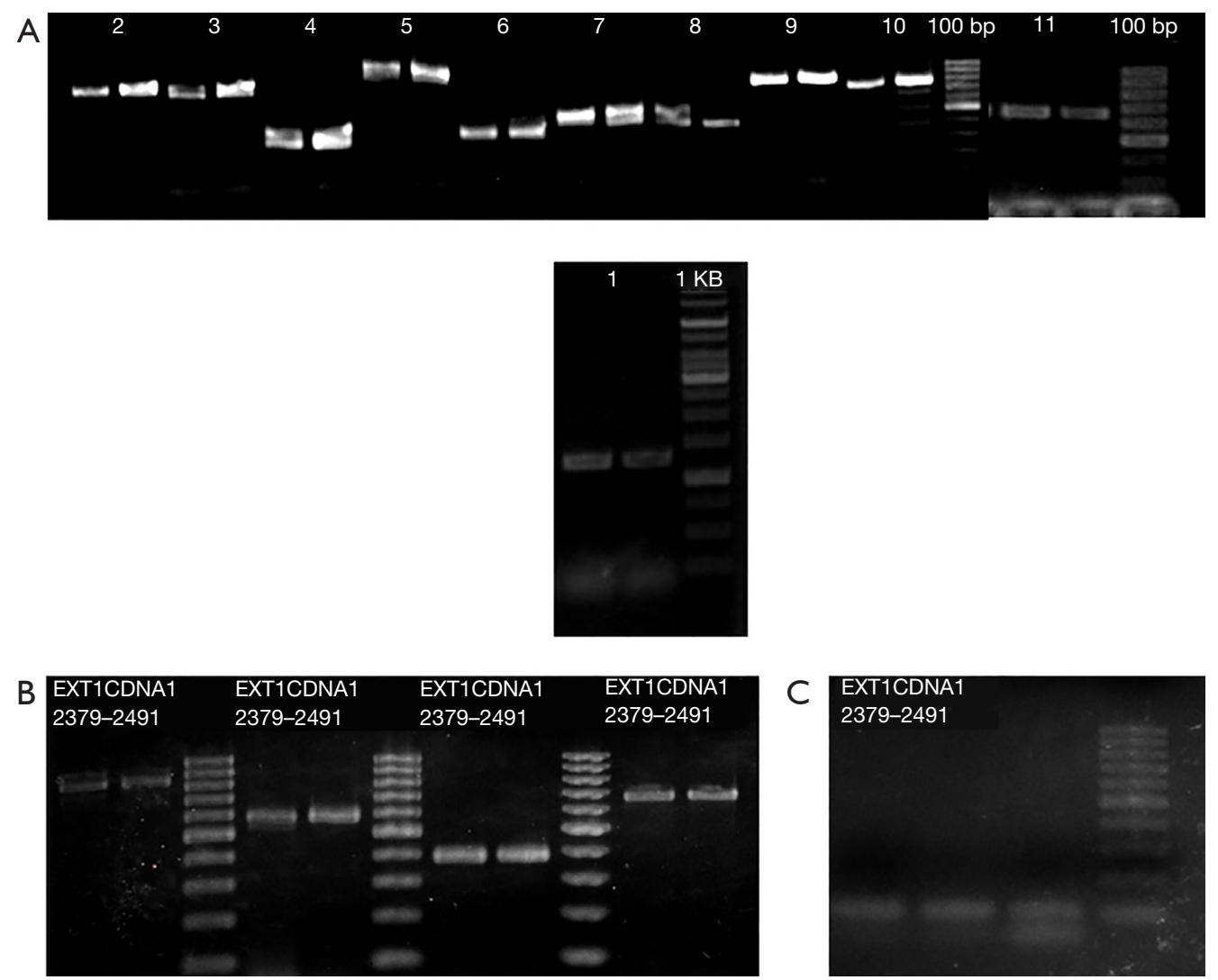

Figure 1 Amplification primer detection. (A) DNA amplification primer detection; (B) RNA amplification primer detection; (C) RNA quantitative amplification primer detection.

located at multiple joints, but most commonly the wrist and knee joints. Spine and iliac joint involvement had not yet occurred, and the patients whose conditions were more severe were younger than the others. The Clinical phenotype of the HME patients was presented in Figure S1.

\section{Sequencing of the EXT1 gene}

To reveal the genetic determinant of HME in the participants, each exon of the EXT1 gene was sequenced. According to the sequencing results on NCBI, the mutation sites on the exon of the EXT1 gene and the amino acid changes were obtained by BLAST alignment and triple codon analysis, respectively (Table 3). The results showed that there were mutations in 4 exons of the EXT1 gene: c.1838 C>T in exon 3; c.2534 G>A in exon 9; c.2702 G>T in exon 10; c. absence of exon 7; and $2397 \mathrm{G}>\mathrm{T}$ in exon7. The mutations included synonymous, deletion, and nonsense mutations; however, there were no frameshift or large-fragment repeated mutations found. Through codon analysis, it was concluded that mutations in the bases of the corresponding exons can cause changes in single nucleotides as follows: the $1838 \mathrm{C} \rightarrow$ T mutation in exon 3 corresponds to cysteine $\rightarrow$ cysteine at 355; the $\mathrm{G} \rightarrow$ A mutation at position 2534 in exon 9 corresponds to valley 587 Glutamate $\rightarrow$ Glutamate; the $2702 \mathrm{G} \rightarrow$ T mutation in exon 10 corresponds to lysine $\rightarrow$ lysine at position 643 ; and the $2397 \mathrm{G} \rightarrow \mathrm{T}$ mutation in exon 7 corresponds to Glutamate to a stop codon at position 542 . Also, the deletion of exon 7 corresponds to the deletion of 32 amino acids. Among these mutations, the deletion of exon 7 and the $2397 \mathrm{G} \rightarrow \mathrm{T}$ mutation on exon 7 have not been reported in previous studies. The presence of the mutation on exon 7 was found in the affected family members but not in the unaffected individuals. Therefore, we may conclude that the novel mutations in EXT1, the absence of exon 7 and $2397 \mathrm{G}>\mathrm{T}$ in exon 7 , were the molecular and 
A

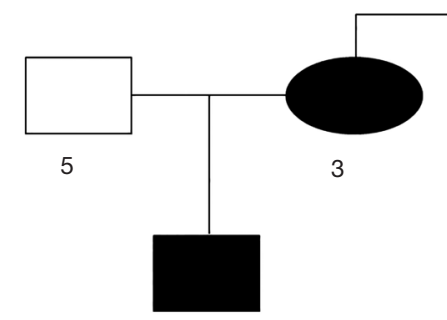

2

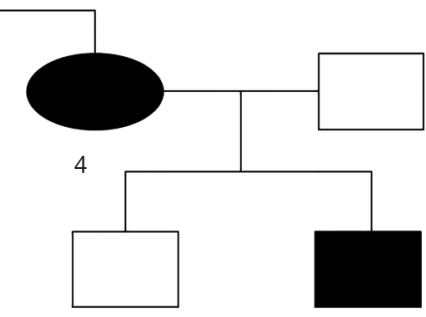

1

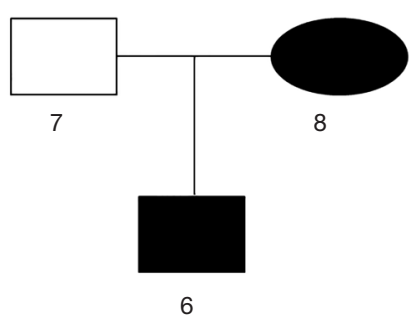

Family 2

Family 1

B

\begin{tabular}{|c|c|c|c|c|c|c|c|c|c|c|c|c|c|c|c|}
\hline \multirow[b]{2}{*}{ NO } & \multirow[b]{2}{*}{$\begin{array}{c}\text { Age of } \\
\text { diagnosis } \\
\text { (yr) }\end{array}$} & \multirow[b]{2}{*}{ Sex } & \multirow[b]{2}{*}{$\begin{array}{c}\text { Number } \\
\text { of } \\
\text { tumor }\end{array}$} & \multicolumn{10}{|c|}{ Affected bone and joint } & \multirow[b]{2}{*}{$\begin{array}{l}\text { Surgery } \\
\text { history }\end{array}$} & \multirow[b]{2}{*}{ Type } \\
\hline & & & & Shoulder & Elbow & Wrist & Hip & Knee & Ankle & Rib & Spine & Hand & llium & & \\
\hline $1(t)$ & 5 & $M$ & 3 & & & + & & & & + & & & & & la \\
\hline $2(+)$ & 12 & M & 25 & + & & + & + & + & + & + & & + & & + & III b \\
\hline $3(+)$ & 35 & $\mathrm{~F}$ & 1 & & & & & + & & & & & & & la \\
\hline $4(+)$ & 39 & M & 1 & & & & & + & & & & & & + & la \\
\hline $5(-)$ & 35 & M & & & & & & & & & & & & & \\
\hline $6(+)$ & 5 & M & 6 & & + & + & & & & & & & & + & III b \\
\hline $7(-)$ & 34 & M & & & & & & & & & & & & & \\
\hline $8(+)$ & 34 & $\mathrm{~F}$ & 2 & & + & + & & & & & & & & & la \\
\hline
\end{tabular}

Figure 2 Clinical data of two families with hereditary multiple exostoses. (A) The pedigree of the two families with hereditary multiple exostoses (HME). The filled shapes represent the affected individuals, while the empty shapes indicate the unaffected family members. The numbers indicate the individuals who were examined and sequenced; (B) the clinical characteristics of the two families included in this study.

Table 3 The mutation sites, corresponding bases, and amino acids in eight patients

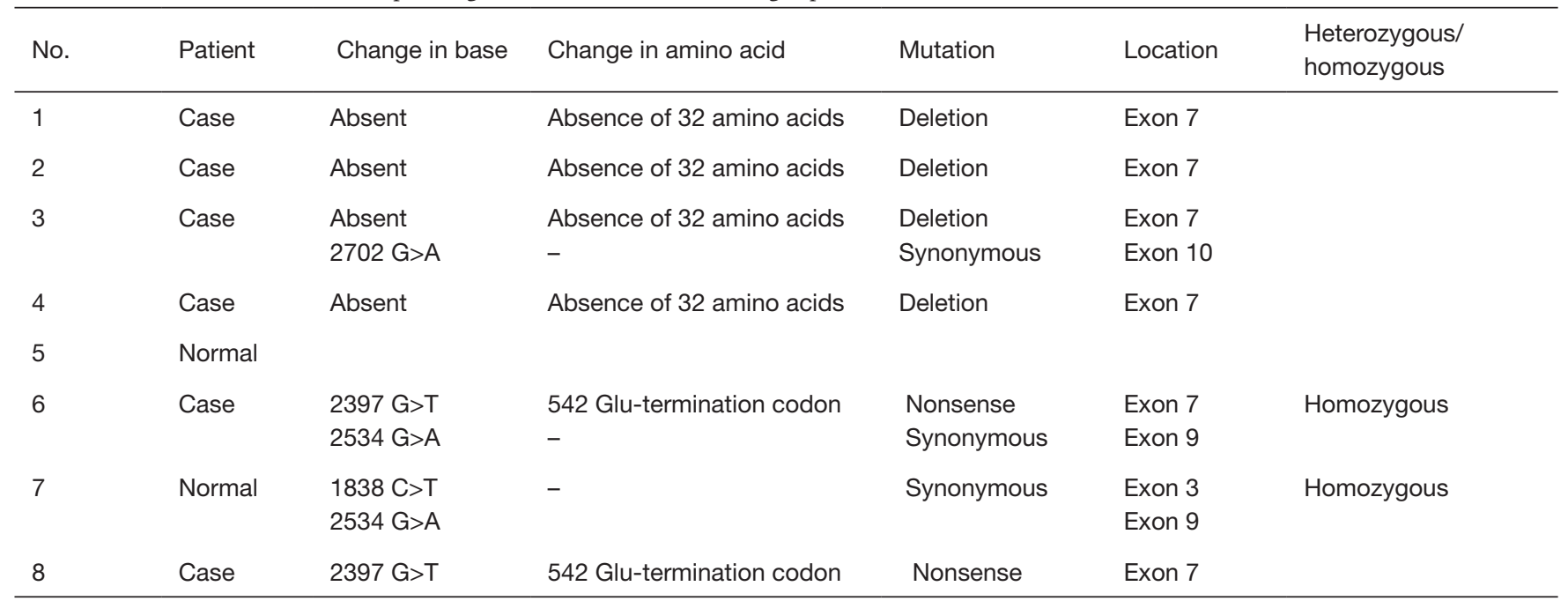

pathophysiological mechanisms underlying HME in patients $1,2,3,4,6$, and 8 .

\section{The validation of mutant gene by Sanger sequencing}

The results of exon sequencing of EXT1 showed that the deletion of exon 7 and $2397 \mathrm{G}>\mathrm{T}$ in exon 7 may exert an impact on gene function. Gene amplification was performed to identify the change of gene expression caused by the mutations. The amplified bands of normal (2310-2405) and mutant samples of exon 7 were 587 and $491 \mathrm{bp}$, respectively (Figure $3 A$ ). The mutant samples were confirmed to be heterozygous for deletion of exon 7 . Sanger sequencing was performed to verify the mutation in the 


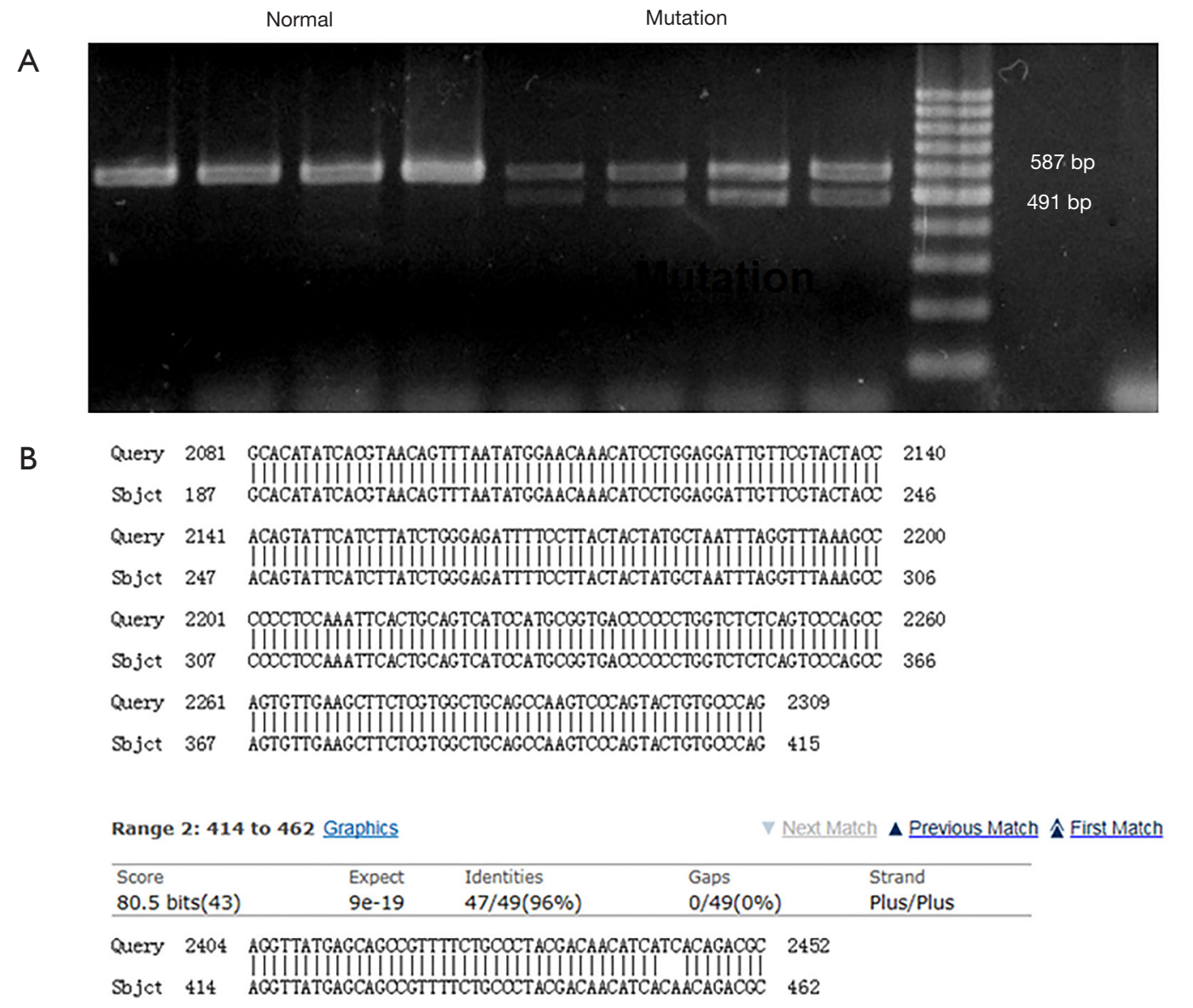
C

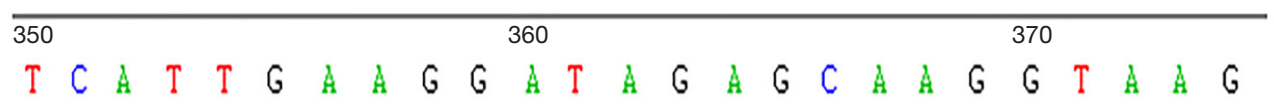

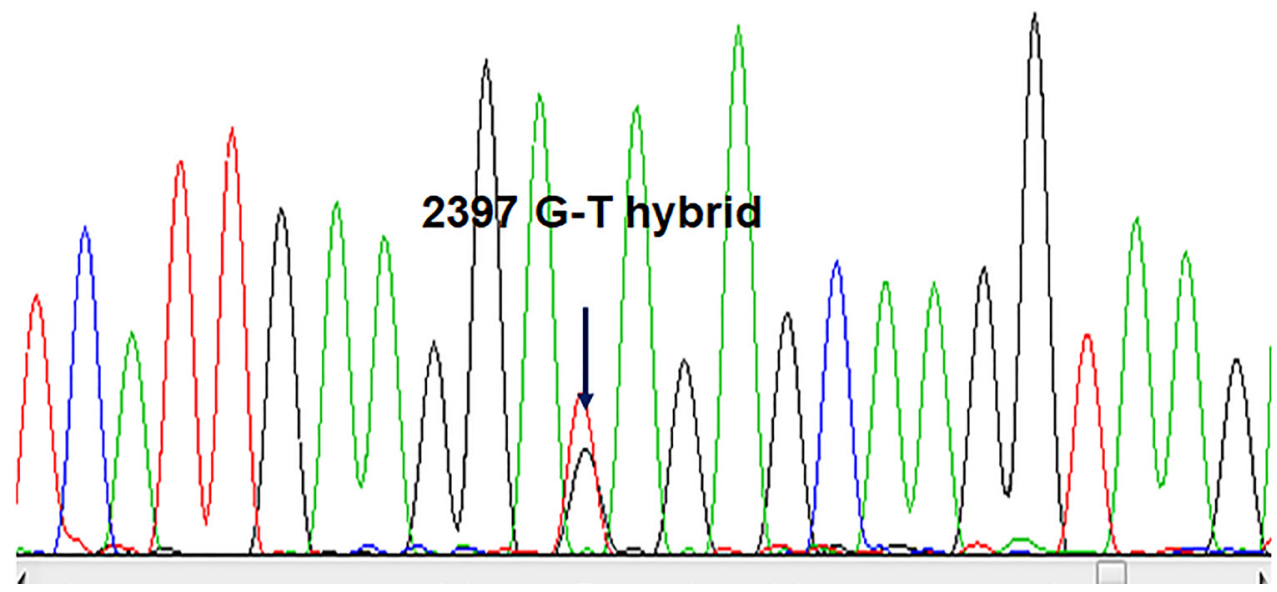

Figure 3 Mutation validation of exons of EXT1 gene in two families with hereditary multiple exostoses. (A) The amplified bands of normal and mutant samples of exon 7 of the EXT1 gene; (B) mutation samples verified by sequencing; (C) sequencing of exons of the EXT1 gene: $2397 \mathrm{G} \rightarrow$ T mutation on exon 7 at amino acid 542 . 


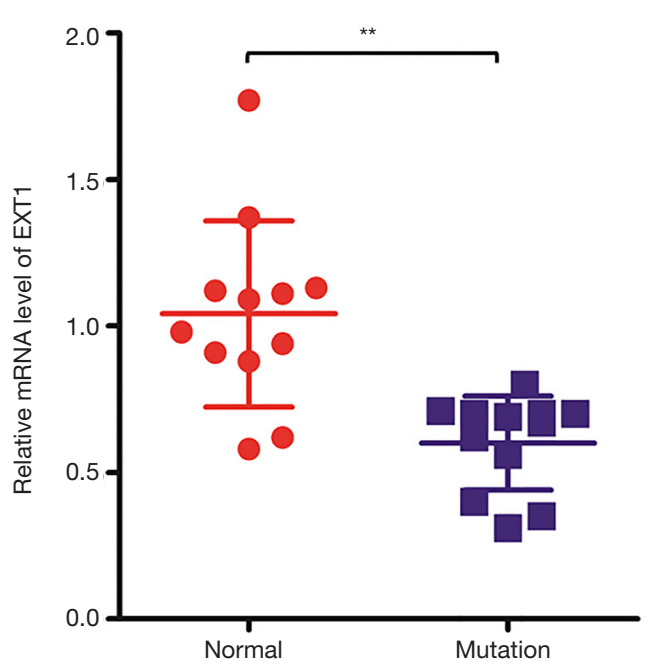

Figure 4 EXT1 mRNA expression in normal and mutation samples $(\mathrm{n}=11)$. ${ }^{* *}, \mathrm{P}<0.01$ vs. normal samples.

mutant samples, and we found that deletion of exon 7 and G>T mutation at base 2397 caused a nonsense mutation at amino acid 542 (Figure 3B,C). As the unaffected relatives did not carry the mutation, deletion of exon 7 and 2397 $\mathrm{G}>\mathrm{T}$ in exon 7 were seen as candidate pathogenic gene mutations.

\section{$m R N A$ expression of EXT1 in mutant samples}

To define the influence of the deletion mutation and nonsense mutation on EXT1 function, we detected mRNA expression of the EXT1 gene by RT-PCR. The results showed that the relative mRNA expression of the EXT1 gene in normal samples was $1.04 \pm 0.31$, and the relative expression of the EXT1 gene in samples with exon 7 deletion and $2397 \mathrm{G}>\mathrm{T}$ mutation was $0.6 \pm 0.14$. The mRNA expression of EXT1 decreased by $40 \%$, and the $\mathrm{P}$ value was $<0.01$ with a statistically significant difference (Figure 4), which indicated that deletion of exon 7 and $2397 \mathrm{G}>\mathrm{T}$ in exon 7 could greatly impact the expression and function of EXT1.

\section{Discussion}

The specific pathological and biochemical mechanisms of HME, an autosomal dominant inheritance cartilage dysplasia, have yet to be fully illuminated. Previous studies have found that the occurrence of HME can be triggered by a variety of factors, including environmental and genetic factors. In particular, genetic mutations play an important role. Our study recruited two families including HME patients and their relatives. These participants were sequenced for the EXT1 gene and the changes of 11 exons in EXT1 were observed. The deletion of exon 7 and the change of base $\mathrm{G}$ to $\mathrm{T}$ at position 2397 in exon 7 have not been reported previously. The mutations on exon 7 truncate mRNA expression of EXT1, which causes abnormal HS synthesis and leads to abnormal chondrocyte differentiation, eventually triggering a series of HME symptoms.

The most common mutations identified in HME patients are frameshift mutations, followed by nonsense mutations. Deletions, especially the deletion of single exon, are rare. Previous studies have shown that the mutations in EXT1 exon are mainly concentrated in four exons (1, 2, 6, and 8), while the sequences of the remaining exons of the EXT1 gene are conservative, which means the mutations do not easily occur. The results of our study revealed that mutations were present in four exons of EXT1 (exon 3, exon 7, exon 9 , and exon 10), most of which were synonymous mutations apart from the deletion mutation and nonsense mutation in exon 7. In recent years, some studies have used exon sequencing or transcriptomics technologies to investigate deletion and nonsense mutations in EXT1 $(14,15)$, but there have been no studies specifically about exon 7 . Exon 7 is 96 bp long and codes for 32 amino acids. Its deletion, which rarely occurs, results in the absence of 32 amino acids. Moreover, the $2397 \mathrm{G}>\mathrm{T}$ mutation in exon 7 corresponds with the occurrence of glutamate, which is a stop codon that shortens the mRNA expression of EXT1. The above mutations could exert an influence on the function of EXT1. The deletion of EXT1, which is a Golgi-type type II transmembrane glycoprotein, can cause a reduction of HSPGs. HSPGs are an essential component of cartilage and are important regulators of chondrocyte proliferation and differentiation in the growth plate. They are widely distributed on the cell membrane and extracellular matrix of somatic cells. In HME, the disorder of HS synthesis could result in tumor formation. In our study, the deletion of exon 7 was mainly concentrated in patients 1, 2, 3, and 4 , and formation of stop codons on exon 7 was mainly concentrated in patients 6 and 8 . These mutations were identified in affected individuals and absent in unaffected individuals. Therefore, it is suggested that the change of exon 7 may be related to the pathogenesis of HME. We validated these changes by Sanger sequencing. The deletion mutation and nonsense mutation brought about the loss of 32 amino acid and truncation of EXT1 expression, which 
may severely disturb the function of EXT1. The results of RT-PCR showed that changes in exon 7 can lead to a $40 \%$ reduction in EXT1 gene expression, indicating that the mutation of exon 7 can affect the function of EXT1 to a considerable extent and rapidly promote the process of HME. The mutations exerted a dominant negative effect on the protein encoded by EXT1. As candidate mutations, deletion and nonsense mutations on exon 7 of the EXT1 gene are closely related to HME.

To conclude, this study identified new mutation sites for the pathogenesis of HME, therefore expanding the existing mutation spectrum and providing new targets for the diagnosis and treatment of HME patients. Our findings will support further investigation into the regulation of bone development and tumor formation in HME, as well as the development of new treatments, and will assist genetic counseling of HME.

\section{Acknowledgments}

Funding: This work was supported by grants from project of Shanghai Municipal Health Planning commission of China (201740087).

\section{Footnote}

Reporting Checklist: The authors have completed the MDAR reporting checklist. Available at http://dx.doi.org/10.21037/ tp-20-191

Data Sharing Statement: Available at http://dx.doi. org/10.21037/tp-20-191

Conflicts of Interest: All authors have completed the ICMJE uniform disclosure form (available at http://dx.doi. org/10.21037/tp-20-191). The authors have no conflicts of interest to declare.

Ethical Statement: The authors are accountable for all aspects of the work in ensuring that questions related to the accuracy or integrity of any part of the work are appropriately investigated and resolved. All procedures performed in this study involving human participants were in accordance with the Declaration of Helsinki (as revised in 2013). The study was approved by Ethics Committee of the Department of Orthopedics of Shanghai Children's Hospital (NO.: 2017023) and informed consent was taken from all the patients.
Open Access Statement: This is an Open Access article distributed in accordance with the Creative Commons Attribution-NonCommercial-NoDerivs 4.0 International License (CC BY-NC-ND 4.0), which permits the noncommercial replication and distribution of the article with the strict proviso that no changes or edits are made and the original work is properly cited (including links to both the formal publication through the relevant DOI and the license). See: https://creativecommons.org/licenses/by-nc-nd/4.0/.

\section{References}

1. Schmale GA, Conrad EU 3rd, Raskind WH. The natural history of hereditary multiple exostoses. J Bone Joint Surg Am 1994;76:986-92.

2. Wicklund CL, Pauli RM, Johnston D, et al. Natural history study of hereditary multiple exostoses. Am J Med Genet 1995;55:43-6.

3. D'Arienzo A, Andreani L, Sacchetti F, et al. Hereditary Multiple Exostoses: Current Insights. Orthop Res Rev 2019;11:199-211.

4. Pacifici M. Hereditary Multiple Exostoses: New Insights into Pathogenesis, Clinical Complications, and Potential Treatments. Curr Osteoporos Rep 2017;15:142-52.

5. Phan AQ, Pacifici M, Esko JD. Advances in the pathogenesis and possible treatments for multiple hereditary exostoses from the 2016 international MHE conference. Connect Tissue Res 2018;59:85-98.

6. Jennes I, Pedrini E, Zuntini M, et al. Multiple osteochondromas: mutation update and description of the multiple osteochondromas mutation database (MOdb). Hum Mutat 2009;30:1620-7.

7. Sarrión P, Sangorrin A, Urreizti R, et al. Mutations in the EXT1 and EXT2 genes in Spanish patients with multiple osteochondromas. Sci Rep 2013;3:1346.

8. Wuyts W, Bovée JV, Hogendoorn PC. From gene to disease; hereditary multiple exostoses. Ned Tijdschr Geneeskd 2002;146:162-4.

9. Wuyts W, Van Hul W, Wauters J, et al. Positional cloning of a gene involved in hereditary multiple exostoses. Hum Mol Genet 1996;5:1547-57.

10. Wuyts W, Van Hul W. Molecular basis of multiple exostoses: mutations in the EXT1 and EXT2 genes. Hum Mutat 2000;15:220-7.

11. Stancheva-Ivanova MK, Wuyts W, van Hul E, et al. Clinical and molecular studies of EXT1/EXT2 in Bulgaria. J Inherit Metab Dis 2011;34:917-21.

12. Pacifici $M$. The pathogenic roles of heparan sulfate 
deficiency in hereditary multiple exostoses. Matrix Biol 2018;71-72:28-39.

13. Huegel J, Sgariglia F, Enomoto-Iwamoto M, et al. Heparan sulfate in skeletal development, growth, and pathology: the case of hereditary multiple exostoses. Dev Dyn 2013;242:1021-32.

14. Oliver GR, Blackburn PR, Ellingson MS, et al. RNASeq detects a SAMD12- EXT1 fusion transcript and

Cite this article as: Shen $\mathrm{Y}$, Zhang L, Chen B, Dong L, Wang Y, Wang S. Novel deletion and 2397 G>T mutations of the EXT1 gene identified in two Chinese pedigrees with hereditary multiple exostoses using exon sequencing. Transl Pediatr 2020;9(5):619-628. doi: 10.21037/tp-20-191 leads to the discovery of an EXT1 deletion in a child with multiple osteochondromas. Mol Genet Genomic Med 2019;7:e00560.

15. Zhuang L, Gerber SD, Kuchen S, et al. Deletion of exon 8 from the EXT1 gene causes multiple osteochondromas (MO) in a family with three affected members.

Springerplus 2016;5:71. 

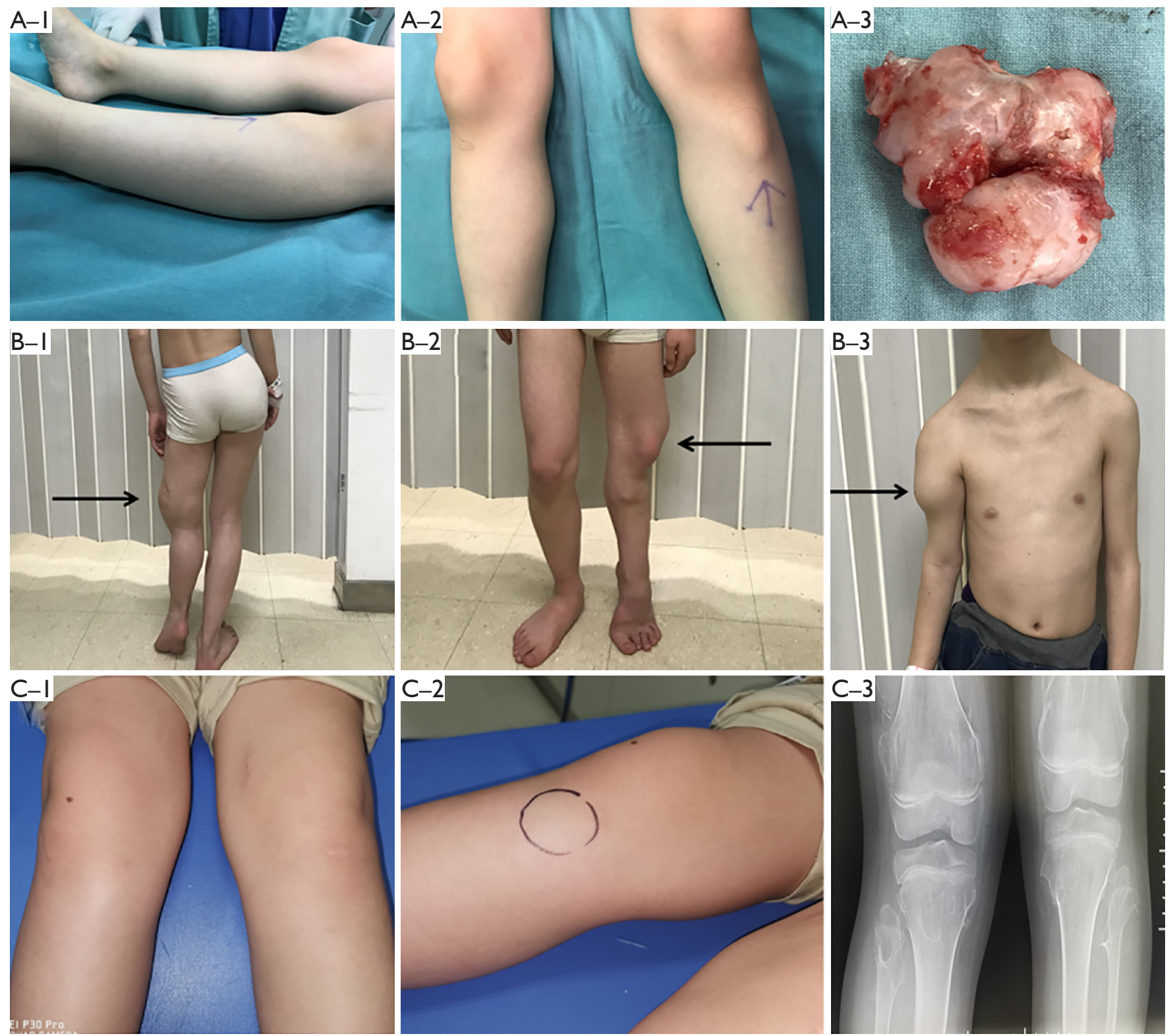

Figure S1 Clinical phenotype of the family enrolled for the exome sequencing analysis. (A1-3) Osteochondroma were indicated with white arrows in the proximal end of the tibias; (B1-3) proximal end of the femurs and humerus; (C1-3) proximal end of the tibias. 